\title{
Economic Growth, Inflation and Wage Growth: Experience from a Developing Country
}

\author{
Shahram Fattahi (Corresponding author) \\ Department of Economics \\ Faculty of Social Sciences, Razi University \\ Shahid Beheshti Blvd, Kermanshah, Iran \\ Tel: 98-831-836-1370Ｅmail: sh_fatahi@yahoo.com
}

Received: January 17, 2012

doi:10.5430/bmr.v1n2p88
Accepted: May 16, 2012

Online Published: June 8, 2012

URL: http://dx.doi.org/10.5430/bmr.v1n2p88

\begin{abstract}
The Iranian economy has been subject to a number of critical events over the past five decades including the 1979 revolution, the eight-year war with Iraq, volatility in global oil prices, and the 1993 balance of payment crisis. These events plus government controls of the major parts of the economy have substantially changed the behavior of the macroeconomic variables. This research tries to examine the behavior of the key macroeconomic variables including economic growth, inflation and wage growth over the period 1959-2007. Based on the estimated multi equation model and applying the three scenarios, the economic growth is predicted to oscillate between $3.28 \%$ and $6.98 \%$. Furthermore, it is forecasted that the inflation rate and the wage growth rate will be increased.
\end{abstract}

Keywords: Economic Growth, Inflation, Forecast, Developing Country

\section{Introduction}

This paper tries to examine the behavior of the key macroeconomic variables including economic growth, inflation and wage growth in the Iranian economy over the period 1959-2007. The Iranian economy is oil-reliant so that any change in oil price can directly affect all economic sectors. It should be noted that Iran ranks second in the world in natural gas reserves and third in oil reserves. It is also OPEC's second largest oil exporter.

The Iranian economy has experienced a relatively high inflation averaging about 15 percent per year. The inflation rate has even been more than 20 percent on average after the 1973 oil crisis. Another major problem is high unemployment in Iran. The unemployment rate increased from 2.8 percent in 1959 to 8.7 percent in 1974 and this increase has continued so that it peaked at 14.4 percent in 1989. Unemployment has been on average more than 9.4 percent for the period 1974-2007.

High inflation along with high unemployment, which is referred to as stagflation, has been the major concerns in Iran's economy. Although the oil shock is the source of stagflation in developed countries, the massive currency depreciation is the main factor for the case of Iran (Bahmani-Oskooee, 1995). In order to remove these problems, the government has taken some actions including trade liberalization, tax reform, exchange rate unification, subsidy reform and financial sector reform. However, little progress has been made in the area of privatization.

Oil revenues have been one of the main sources of money creation, fueled by government spending. Another important factor for increasing liquidity (M2) is the large number of government-controlled enterprises which increase the budget deficit through borrowing from the Central Bank, and thus increase the monetary base. Money supply growth has been 25.17 percent on average for the period 1959-2007, whereas real GNP growth recorded only on average 6.33 percent during the same period. Furthermore, money supply has become 42166 fold while real GNP recorded only a 14 fold increase during the same period. As the same time population has been growing, resulting in an increasing demand which adds to inflation pressure.

The rest of this paper is organized as follows. Section 2 presents the model to be estimated and describes all the data used. Section 3 reports the empirical results of the study. Finally, section 4 concludes.

\section{A multi-equation model}

The multi-equation model to be estimated consists of three equations. The first equation is the wage equation: 


$$
\begin{gathered}
W=\alpha_{0}+\alpha_{1} U+\alpha_{2} O G+\alpha_{3} \pi+\alpha_{4} \pi^{e} \\
\alpha_{1}<0, \alpha_{2}, \alpha_{3}, \alpha_{4}>0
\end{gathered}
$$

where $W$ is nominal wage growth rate, $U$ unemployment rate, $O G$ output gap, $\pi$ inflation rate, and $\pi^{e}$ expected inflation rate. Equation (1) is the expectations-augmented Phillips curve. The output gap is defined as the percentage deviation of real GNP from its long-term trend (derived by the Hodrick-Prescott filter)

$$
O G=\frac{y-y^{*}}{y^{*}}
$$

where $y$ is real GNP and $y^{*}$ is the potential output of the economy. The unemployment rate (U) is a proxy for excess supply of labor. An increase in $\mathrm{U}$ will result in a decrease in $\mathrm{W}$ so that one expects $\alpha_{1}<0$. Since $y$ is a proxy for the demand for labor and there is a positive relationship between $y$ and $O G$, one would expect $\alpha_{2}>0$. The increases in wages caused by increases in prices are given by the equation $W=M P_{L} \cdot P$, where $M P_{L}$ is the marginal product of labor. The role of price inflation and expected price inflation in the determination of wages has been emphasized by many researchers (Lahiri, 1981; Chen and Flaschel, 2006).

In a competitive economy, the expected inflation should have a coefficient equal to unity while in noncompetitive situations it lies between zero and unity depending on the strength of unions and other noncompetitive elements in the bargaining process. (Turnovsky and Wachter, 1972). Furthermore, the expected inflation coefficient will be unity only if workers can fully account for the amount of expected inflation in their current wage settlements. According to the natural rate hypothesis, there is no way for the government to keep the unemployment rate permanently below the natural rate. Therefore, there is no long-run trade-off between inflation and unemployment, which implies that the coefficient of expected inflation will be unity.

Equation (2) is the aggregate demand function

$$
\begin{gathered}
y=\beta_{0}+\beta_{1}\left(M_{2} / P\right)+\beta_{2} g+\beta_{3} c-1+\beta_{4} D \\
\beta_{1}, \beta_{2}, \beta_{3}>0, \beta_{4}<0
\end{gathered}
$$

where $M_{2} / P$ is real money ( $M_{2}$ broad money and $P$ the implicit price deflator), $g$ real government expenditure, $c$ real consumption, and $D$ dummy variable. This function can be derived as a solution of IS-LM relationships, with the lagged value of $\mathrm{c}$ introduced to make the implied consumption function of permanent-income hypothesis and the dummy variable included to capture the effect of the 1979 revolution on production. All variables in equation (2) except the dummy variable will be employed in the growth rates.

Equation (3) determines price level changes as

$$
\begin{array}{r}
\pi=\gamma_{0}+\gamma_{1} M_{2}+\gamma_{2} X+\gamma_{3} \pi^{m}+\gamma_{4} T \\
\gamma_{1}, \gamma_{3}, \gamma_{4}>0, \gamma_{2}<0
\end{array}
$$

where $X$ is the labor productivity measured as the ratio of real GNP to employment, $\pi^{m}$ import inflation, and $T$ is the trend variable. The variables $M_{2}$ and $X$ will be used in the growth rates. Bahmani-Oskooee (1995), Liu and Adedeji (2000), Valadkhani (2006) and Bonato (2007) have supported money supply growth as one of the main determinants of inflation in Iran. It should be noted that wages are not the cause of inflation in Iran because labor unions do not have enough power and play no determining role in the economy.

Since all equations are over-identified, applying the ordinary least square (OLS) method to the equations will be inappropriate. One solution to this problem is to use two-stage least square procedure (2SLS). Table 1 displays summary statistics of the data including the mean, the maximum, the minimum, and the standard deviation for the period 1959-2007. The data are annually and are collected from the Central Bank of Iran. Before running the regressions, we examined whether the data are stationary. The empirical results of the Augmented Dicky-Fuller test indicated that all the variables employed are stationary, and thus this issue helps us to avoid the problem of the spurious relationships.

\section{Empirical results}

\subsection{Estimation}

In order to estimate the multi equation model parameters, the process of expectation formation should be determined. An adaptive learning model, which is a more realistic way of modeling expectation formation, will be employed 
(Evans and Honkapohja, 2001; Orphanides and Williams, 2002; Basdevant, 2005). Neither backward-looking models (for instance, adaptive expectations model) and nor models with rational expectations are reasonable and realistic because the former assumes that historical econometric relationships are invariant to changes in the economic policy and that agents do not react to systematic mistakes they made while the latter assumes that agents fully know the structure of the economy and form their expectations accordingly.

Since private agents are not endowed with a priori knowledge of inflation behavior, they must learn about it over time as new data becomes available (Sargent, 1999). Although much research has been done on adaptive learning models in recent years, they are largely theoretical (Bernanke, 2003). In this study, expected inflation is generated through a least square learning rule and then expected inflation is analyzed in the augmented Phillips curve equation. An econometric tool to study learning is the Kalman filter which can be used to estimate time-varying economic relationships.

The learning approach assumes that the agents' expectations of inflation are on average correct but a limited set of information is used. It is assumed that agents forecast inflation using $\pi_{t-1}$ and $y_{t-1}$ through recursive least squares (RLS)

$$
\pi_{t \mid \mathrm{t}+1}=b_{1, t}+b_{2, t} \pi_{t-1}+b_{2, t} y_{t-1}+\varepsilon_{t}
$$

where $\pi_{t \mid t+1}$ is the inflation rate in the next period expected by the agents at time $t$. Agents forecast inflation in the next period by updating the parameters period by period. The process of updating is based on RLS as follows (Bullard 1992, Sargent 1999, Evans and Honkapohja 2001)

$$
\begin{gathered}
B_{t}=B_{t-1}+t^{-1} R_{t}^{-1} X_{t}\left(\pi_{t}-X_{t}^{\prime} B_{t-1}\right) \\
R_{t}=R_{t-1}+t^{-1}\left(X_{t} X_{t}^{\prime}-R_{t-1}\right)
\end{gathered}
$$

where $B_{t}=\left(b_{1, t}, b_{2, t}, b_{3, t}\right)^{\prime}$ and $X_{t}=\left(1, \pi_{t-1}, y_{t-1}\right)$. The equations above correspond to the following state space model:

$$
\begin{gathered}
\pi_{t \mid \mathrm{t}+1}=b_{1, t}+b_{2, t} \pi_{t-1}+b_{2, t} y_{t-1}+\varepsilon_{t} \\
b_{i, t}=b_{i, t-1}+v_{i, t}
\end{gathered}
$$

The expected inflation is computed as the predicted value for $\pi_{t \mid t+1}$. The results of the estimated multi equation model are as follows ( $\mathrm{p}$-value in parenthesis):

$$
\begin{aligned}
& W=17.38-1.57 U+0.37 O G+0.58 \pi+0.60 \pi^{e} \quad \bar{R}^{2}=0.55 \quad D W=1.68 \\
& (0.001)(0.0001)(0.002)(0.0001)(0.0001) \\
& y=-0.09+0.53\left(M_{2} / P\right)+0.3 g-20.91 D \quad \bar{R}^{2}=0.54 \quad D W=1.90 \\
& (0.96)(0.002)(0.003)(0.0000) \\
& \pi=-2.27+0.29 M_{2}-0.36 X+0.39 \pi^{m}+0.25 T \quad \bar{R}^{2}=0.71 \quad D W=1.89
\end{aligned}
$$

(0.46) (0.02) (0.03) (0.0000) (0.001)

Since there was evidence of autocorrelation in the wage equation, the estimated function was corrected for this problem. The result from diagnostic checking show the model does not suffer from heteroscedasticity. In the income equation, lagged real consumption was excluded from specification because this variable was not significant. All coefficients of the explanatory variables in the multi equation model have the expected signs and are statistically significant. In the wage equation, a higher unemployment rate is associated with a lower wage growth rate while higher output gap increases wage growth rate. The expected inflation is the most important determinant of changes in wages. The size of the coefficient of expected inflation (0.60) is relatively large, even larger than the coefficient of actual inflation (0.58). It means that the wage growth rate is more sensitive to the expected inflation than the actual inflation. Inflation expectations are very unstable in Iran's economy because the Central Bank is unable to adhere to an inflation target in practice. Thus, inflation expectations are not well-anchored and any oil price increase, which seems apparently to be a favorable shock, results in money creation, fueled by government spending out of oil revenues, and inflation. 
In the income equation, real growth rate of $\mathrm{M} 2$ and real growth rate of government expenditure are positively associated with economic growth while the production has decreased due to the 1979 revolution. In the last equation, the import price growth rate is the most important determinant of changes in prices. The trend variable and nominal growth rate of M2 have almost the same positive effect on inflation rate, 0.25 and 0.29 respectively. Finally, the coefficient of the labor productivity is negative as expected.

\subsection{Policy Scenarios}

Three scenarios are implemented with different assumptions namely Scenario I (baseline scenario), Scenario II and Scenario III. In Scenario I, it assumed that long run trends in endogenous variables as well as exogenous variables will continue to hold over the next five years. In this case, a time series method is implemented to produce the projections for future values of the all variables. A collection of ARMA (p, q) models, for different orders of $p$ and $q$, have been estimated and then the best model was selected according to the Akaike information criterion (AIC) and the Schwarz information criterion (SIC). The results indicated that the ARMA $(1,1)$ model does a reasonably good job for most variables. Table 2 shows the averages of the actual values over the period 1959-2007 and the averages of predicted values over the period 2008-2012.

It is of special interest to examine the behavior of the three endogenous variables (i.e. $w, y$ and $\pi$ ). While the average wage growth rate $(\mathrm{w})$ was $17.39 \%$ over the last 50 years, it is forecasted to rise to $29.52 \%$ over the period $2008-2012$ in the baseline scenario. The average inflation rate $(\pi)$ is predicted to be $18.41 \%$ over the next 5 years. However, the average economic growth rate $(\mathrm{y})$ is expected to increase slightly over the prediction period. It will increase from $6.33 \%$ to $6.98 \%$.

Scenario II takes into account the long run trends only in exogenous variables in a different way. In doing so, first, averages of the actual values of the exogenous variables are calculated over the period 1959-2007. Then averages of predicted values of the endogenous variables can be obtained by substituting averages of the actual values of the exogenous variables into the estimated wage, income and price equations. Scenario III is similar to Scenario II but the recent trends in exogenous variables will be considered. In fact, averages of the actual values of the exogenous variables are calculated over the period 1989-2007. The results of the predicted endogenous variables under three scenarios have been presented in Table 3. Under all three scenarios, it is forecasted that the inflation rate and the wage growth rate will be increased over the period 2008-2012, as compared to the averages of corresponding values, for instance $15.13 \%$ and $17.39 \%$ respectively. Furthermore, more inflation and higher wage growth are expected if the subsidy reform plan is implemented. The economic growth is also predicted to oscillate between $3.28 \%$ and $6.98 \%$.

\section{Conclusions}

The study examined the behavior of the key macroeconomic variables including wage growth, economic growth, and inflation using a multi equation model. The results indicated that the actual inflation and the expected inflation are positively associated with wage growth rate. Furthermore, the inflation expectations play a major role in the determination of the wages.

Economic growth has been $6.33 \%$ on average over the period 1959-2007. However, this growth in Iran has not been sustainable. Furthermore, it should be noted that money supply has become 42166 fold while real GNP recorded only a 14 fold increase during the same period.

The Iranian economy has experienced a relatively high inflation with an average inflation rate of about 15 percent over the period 1959-2007. It has even been more than 20 percent on average after the 1973 oil crisis. The import price growth rate has been the most important determinant of changes in prices. The trend variable and nominal growth rate of M2 have almost the same positive effect on inflation rate. It should be noted that oil revenues have been one of the main sources of money creation, fueled by government spending. Another important factor for increasing liquidity (M2) is the large number of government-controlled enterprises which increase the budget deficit through borrowing from the Central Bank, and thus increase the monetary base. Money supply growth has been 25.17 percent on average for the period 1959-2007.

Finally, three scenarios were implemented with different assumptions. Under all three scenarios, it is forecasted that the inflation rate and the wage growth rate will be increased over the period 2008-2012. The economic growth is also predicted to oscillate between $3.28 \%$ and $6.98 \%$.

\section{References}

Bahmani-Oskooee, M. (1995). Source of Inflation in Post-Revolutionary Iran. International Economic Journal. 9(2). 
61-72.

Basdevant, O. (2005). Learning Process and Rational Expectations: An Analysis Using a Small. Macroeconomic Model for New Zealand. Economic. Modelling. 22(6). 1074-1089. http://dx.doi.org/10.1016/j.econmod.2005.07.002

Bernanke B. S. (2003). A Perspective on Inflation Targeting. [Online] Available: http://www.federalreserve.gov/boarddocs/speeches/2003/20030325/default.htm (March 25, 2003).

Bonato L. (2007). Money and Inflation in the Islamic Republic of Iran. [Online] Available: http://www.imf.org/external/pubs/ft/wp/2007/wp07119.pdf. (May, 2007)

Bullard, J. (1992). Time-varying parameters and non-convergence to rational expectations under least square learning. Economic Letters. 40(2). 159-166. http://dx.doi.org/10.1016/0165-1765(92)90216-L

Chen P. \& Flaschel P. (2006). Measuring the Interaction of Wage and Price Phillips Curves for the U.S. Economy. Studies in Nonlinear Dynamics \& Econometrics. 10(4). 1-35. http://dx.doi.org/10.2202/1558-3708.1255

Evans, G. \& Honkapohja S. (2001). Learning and expectations in macroeconomics, Princeton University Press, Princeton, (Chapter 1).

Lahiri, K. (1981). The econometrics of inflationary expectations, North-Holland Pub. Co. (Chapter 3).

Liu O. \& Adedeji O. (2000). Determinants of Inflation in the Islamic Republic of Iran: A Macroeconomic Analysis. [Online] Available: www.imf.org/external/pubs/ft/wp/2000/wp00127.pdf. (July, 2000).

Orphanides A. and Williams J. C. (2002). Imperfect knowledge, inflation expectations and monetary policy. [Online] Available: http://www.federalreserve.gov/pubs/feds/2002/200227/200227pap.pdf. (May, 2002).

Sargent, T. J. (1999). The Conquest of American Inflation, Princeton University Press. (Chapter 2).

Turnovsky, S .J. \& Wachter, M. L. (1972). A Test of the "Expectations Hypothesis" Using Directly Observed Wage and Price Expectations. The Review of Economics and Statistics, MIT Press. 54(1). 47-54. http://dx.doi.org/10.2307/1927494

Valadkhani, A. (2006). Macroeconometric Modelling in an Oil-Exporting Country: The case of Iran. The Journal of Energy and Development. 31(2). 261-282.

Table 1. Descriptive Statistics of the data (1959-2007)

\begin{tabular}{|l|l|l|l|l|}
\hline Variable & Mean & Maximum & Minimum & Std. dev. \\
\hline Wage growth arte (\%) $(\mathrm{W})$ & 17.39 & 47.47 & -6.24 & 12.00 \\
\hline Unemployment rate (\%) (U) & 9.43 & 14.40 & 2.80 & 4.12 \\
\hline Output Gap(\%) (OG) & 0.26 & 38.80 & -28.44 & 14.94 \\
\hline Inflation rate (\%) $(\pi)$ & 15.13 & 44.75 & -2.62 & 11.94 \\
\hline Real GNP growth rate (\%) $(y)$ & 6.33 & 46.12 & -22.93 & 11.57 \\
\hline Nominal growth rate of M2 (\%) $\left(M_{2}\right)$ & 25.17 & 57.06 & 6.02 & 9.45 \\
\hline Real growth rate of M2 (\%) $\left(M_{2} / P\right)$ & 9.57 & 38.85 & -14.45 & 11.40 \\
\hline Real growth rate of government expenditure $(\%)(g)$ & 6.18 & 61.76 & -20.57 & 13.45 \\
\hline Real growth rate of consumption $(\%)(c)$ & 5.28 & 31.47 & -10.13 & 6.98 \\
\hline Import price growth rate $(\%)\left(\pi^{m}\right)$ & 13.38 & 71.89 & -2.06 & 14.22 \\
\hline Productivity growth rate $(\%)(X)$ & 3.69 & 43.05 & -24.70 & 11.22 \\
\hline
\end{tabular}


Table 2. Endogenous and Exogenous Variables under Scenario I (\%)

\begin{tabular}{|c|c|c|c|c|c|}
\hline Variable & $1959-2007$ & $2008-2012$ & Variable & $1959-2007$ & $2008-2012$ \\
\hline $\mathrm{W}$ & 17.39 & 29.52 & $M_{2}$ & 25.17 & 27.21 \\
\hline $\mathrm{U}$ & 9.43 & 10.81 & $M_{2} / P$ & 9.57 & 10.71 \\
\hline $\mathrm{OG}$ & 0.26 & 1.28 & $\mathrm{~g}$ & 6.18 & 2.30 \\
\hline$\pi$ & 15.13 & 18.41 & $\pi^{m}$ & 13.38 & 13.74 \\
\hline$\pi^{e}$ & 15.48 & 17.38 & $\mathrm{X}$ & 3.69 & 4.36 \\
\hline $\mathrm{Y}$ & 6.33 & 6.98 & & & \\
\hline
\end{tabular}

Table 3. Endogenous Variables under three Scenarios (\%)

\begin{tabular}{|c|c|c|c|c|c|}
\hline \multicolumn{2}{|c|}{ Scenario I } & \multicolumn{2}{c|}{ Scenario II } & \multicolumn{2}{c|}{ Scenario III } \\
\hline Variable & $2008-2012$ & Variable & $2008-2012$ & Variable & $2008-2012$ \\
\hline $\mathrm{w}$ & 29.52 & $\mathrm{w}$ & 20.73 & $\mathrm{~W}$ & 23.77 \\
\hline $\mathrm{y}$ & 6.98 & $\mathrm{y}$ & 6.83 & $\mathrm{Y}$ & 3.28 \\
\hline$\pi$ & 18.41 & $\pi$ & 21.92 & $\pi$ & 18.17 \\
\hline
\end{tabular}

